\title{
High light stress regimen on Dunaliella salina strains for carotenoids induction
}

\author{
Anh Nguyen ${ }^{1}$, Dat Tran ${ }^{1}$, Minh Ho ${ }^{2}$, Clifford Louime ${ }^{3}$, Hanh Tran ${ }^{1}$ and Duc Tran ${ }^{1,4 *}$ \\ ${ }^{1}$ School of Biotechnology, International University-Vietnam National University, Vietnam \\ ${ }^{2} \mathrm{~S} a \mathrm{i}$ Gon University, Ho Chi Minh City, Vietnam \\ ${ }^{3}$ College of Natural Sciences, University of Puerto Rico, San Juan, PR00931, USA \\ ${ }^{4}$ Algae2Omega Holdings, Vero Beach, FL 32968, USA
}

\begin{abstract}
The microalgae Dunaliella salina is the richest source of commercial $\beta$-carotene known to man. This natural compound has been proven invaluable in medicine, industry and other fields of science, due to its provitamin A activity and potential disease suppression, as well as usage as a supplement for food and animal feed including as additive to food and cosmetics. However, $\beta$-carotene content in Dunaliella cells depends heavily on growth conditions and nutrient parameters. A set of experiments was conducted to determine the optimum high light stress regimen for Dunaliella salina to achieve the highest carotenoids induction. Three $D$. salina strains (D. salina CCAP 19/18,D. salina A9 and D. bardawil) were cultured in MD4 1.5M medium under stress condition at different regimens for a period of 26 days. Following the first phase of exponential growth, 3 different growth cycles were tested: a cycle of three-day at $800 \mu \mathrm{mol}$. photons $/ \mathrm{m}^{2} / \mathrm{s}$ and one day at $50 \mu \mathrm{mol}$.photons/ $\mathrm{m}^{2} / \mathrm{s}$, a cycle of one day at $800 \mu \mathrm{mol}$.photons $/ \mathrm{m}^{2} / \mathrm{s}$ and three-day at $50 \mu \mathrm{mol}$.photons $/ \mathrm{m}^{2} / \mathrm{s}$ and finally an all-time stress at $800 \mu \mathrm{mol}$. photons $/ \mathrm{m}^{2} / \mathrm{s}$. Total carotenoids were analyzed over the experimental period, including the antioxidant capacities and total phenolic contents of the algal carotenoid extract were simultaneously evaluated. Result revealed that all three D. salina strains produced the highest concentration of total carotene under the all-time stress regimen of $800 \mu$ mol.photons/ $\mathrm{m}^{2} /$ s, and D. salina CCAP had higher total carotenoid content than D. salina A9 and D. bardawil in all stress conditions. This study could surely serve as the basis for scaling up this process to industrial-level applications, which will undoubtedly require further investigation and evaluation of the extraction and testing procedures.
\end{abstract}

\section{Introduction}

Currently there are 26 known or reported species of Dunaliella. These include among others Dunaliella salina, Dunaliella bardawil, Dunaliella tertiolecta [1-5]. Dunaliella salina is a type of unicellular and halophilic green biflagellate microalga without a rigid cell wall structure which can grow at very high salinities and levels of irradiance [6-9].

Dunaliella salina accumulates massive amounts of $\beta$-carotene in electrodense globules located within the inter-thylakoid spaces in the chloroplast. Various stress factors are known to interrupt the physiological balance of a normal Dunaliella salina cell. Therefore, in order to protect itself and continue to grow, Dunaliella cell generates additional $\beta$-carotene restoring its physiology balance under stress conditions [10].

Carotenoids are organic pigments that are known to be crucial for normal vision and have been associated with reducing the risk of several degenerative diseases, including cancer $[11,12]$. $\beta$-carotene is perhaps the most important carotenoid from over 600 types of carotenoids found in nature. It is highly valuable due to its nutritional benefit as a precursor of vitamin A and for its properties such as a color additive, antioxidant, anticancer, antiaging and immunomodulatory $[13,14]$.

Recently, the rate and extent of carotenoid accumulation in Dunaliella salina has been researched under various stress conditions such as high salinity $[15,16]$, high temperature $[17,18]$ and these types of relationship are well established. However, according to scientific community, there are no reports on carotenoids induction in D. salina cultured under different high light stress regimens. Therefore, the aim of this study was to select the most appropriate high light stress regimen for culturing $D$. salina strains to produce economically viable high concentrations of carotene.

\section{Materials and methods \\ Dunaliella salina strains and experimental design}

Three Dunaliella salina strains were grown and maintained in modified natural seawater medium 1.5M (MD4) [19]. The medium contained $\mathrm{NPK}^{\star} 0.1 \mathrm{~g} / \mathrm{l}, \mathrm{MgSO}_{4} 1.86 \mathrm{~g} / \mathrm{l}$, EDTA $0.00876 \mathrm{~g} / \mathrm{l}, \mathrm{FeCl}_{3}$ $0.00049 \mathrm{~g} / \mathrm{l}, \mathrm{MnCl}_{2} 0.00189 \mathrm{~g} / \mathrm{l}, \mathrm{NaCl} 1.5 \mathrm{M}, \mathrm{NaHCO}_{3} 50 \mathrm{mM}$. PH was adjusted to $7.5 \pm 0.5$. ( ${ }^{*} \mathrm{~N}-\mathrm{P}-\mathrm{K}(30-15-10): 30 \% \mathrm{~N}, 15 \% \mathrm{P} 2 \mathrm{O} 5,10 \%$ $\mathrm{K} 2 \mathrm{O}, 0.05 \% \mathrm{Mg}, 0.05 \% \mathrm{Ca}, 0.01 \% \mathrm{~B}, 0.05 \% \mathrm{Zn}, 0.05 \% \mathrm{Cu}, 0.05 \% \mathrm{Fe}$, $0.025 \% \mathrm{Mn}, 0.005 \% \mathrm{Mo}$.).

$30 \mathrm{ml}$ of algal culture was grown in $50 \mathrm{ml}$-flasks with initial cell concentration of $1 \times 10^{5}$ cells $/ \mathrm{ml}$. Samples were manually mixed daily. Each strain was grown with three replicates. Cultures were maintained at room temperature and light intensity of $50 \mu \mathrm{mol}$.photons $/ \mathrm{m}^{2} / \mathrm{s}$ (measured by Digital light intensity meter, LITEcheck) for the first 10 days. At day 11, samples were stressed by maintaining high light

Correspondence to: Duc Tran, Algae2Omega Holdings, 7625 17th Street, Vero Beach, FL 32968, USA, E-mail: tnducminh@yahoo.com

Key words: algae, antioxidant, carotene, Dunaliella, phenolic

Received: September 01, 2016; Accepted: September 15, 2016; Published: September 19, 2016 
intensity of $800 \mu \mathrm{mol}$.photons $/ \mathrm{m}^{2} / \mathrm{s}$ with different regimens: a cycle of three-day at $800 \mu \mathrm{mol}$.photons $/ \mathrm{m}^{2} / \mathrm{s}$ and one day at $50 \mu \mathrm{mol}$.photons/ $\mathrm{m}^{2} / \mathrm{s}$, a cycle of one day at $800 \mu \mathrm{mol}$.photons $/ \mathrm{m}^{2} / \mathrm{s}$ and three-day at $50 \mu \mathrm{mol}$.photons $/ \mathrm{m}^{2} / \mathrm{s}$ and the all-time stress treatment at $800 \mu \mathrm{mol}$. photons $/ \mathrm{m}^{2} / \mathrm{s}$. The experiment was conducted over a 26 -day period.

\section{Growth analysis}

Cell density was calculated by undertaking cell counts every two or three days by direct counting, using a light microscope with $0.1 \mathrm{~mm}$ deep counting chamber (NeubauerHaemocytometer). Lugol solution (5\% iodine and $10 \%$ potassium iodide mixed in distilled water) was used to immobilize cells for counting. Cell number was determined by the following formula:

Number of cells $/ \mathrm{ml}=$ total cells counted $\mathrm{x} 10^{4} \mathrm{x}$ dilution factor

\section{Pigment analysis}

For chlorophyll and carotenoid determination, $1 \mathrm{ml}$ of algae suspension was centrifuged at $1000 \mathrm{xg}$ for $5 \mathrm{~min}$ and the resultant pellet extracted with $3 \mathrm{ml}$ of ethanol: hexane $(2: 1 \mathrm{v} / \mathrm{v})$. Two milliliters of water and $4 \mathrm{ml}$ of absolute hexane were then added and the mixture was vigorously shaken and centrifuged again at 1000xg for $5 \mathrm{~min}$. The top hexane layer was separated and its absorbance was determined: $\mathrm{A}_{450}$ $\mathrm{x} 25.2$ equal to the micrograms of total carotene in sample [20]. The absorbance's (A662, A645, and A450) were read by Microplate Reader (Biotek). Chlorophyll a \& b were estimated according to Lichtentaler and Wellburn formulas (1985):

$$
\begin{aligned}
& \text { Chl } a(\mu \mathrm{g} / \mathrm{ml})=11.75\left(\mathrm{~A}_{662}\right)-2.35\left(\mathrm{~A}_{645}\right) \\
& \text { Chl } b(\mu \mathrm{g} / \mathrm{ml})=18.61\left(\mathrm{~A}_{645}\right)-3.96\left(\mathrm{~A}_{662}\right) \\
& \text { Where: Chl } a \text { : chlorophyll a, Chl } a \text { : chlorophyll b }
\end{aligned}
$$

\section{Antioxidant capacity}

DPPH (2,2-diphenyl-1-picryl-hydrazyl-hydrate) stock solution was prepared by dissolving $0.004 \mathrm{~g}$ of DPPH in $100 \mathrm{ml}$ of methanol $[21,22]$. One $\mathrm{ml}$ of $D$. salina was centrifuged at $10000 \mathrm{rpm}$ at $4^{\circ} \mathrm{C}$ for $15 \mathrm{~min}$ and the pellet was extracted with $1 \mathrm{ml}$ of absolute ethanol and vortexed well. The extract was incubated at $4^{\circ} \mathrm{C}$ for 4 hours and centrifuged at $5000 \mathrm{rpm}$ for $5 \mathrm{~min}$. Then, the mixture was added to $2 \mathrm{ml} \mathrm{DPPH}$ solution and left to stand for $30 \mathrm{~min}$ in the dark at room temperature. The absorbance of the extract at $517 \mathrm{~nm}$ was determined spectrophotometrically. A blank sample (absolute ethanol) was utilized for control. The antioxidant activity was calculated based on the inhibition of free radical DPPH percent according to the formula:

$\mathrm{I} \%=($ Ablank - Asample $) /$ Ablank x 100

\section{Total phenolic content}

Total phenolic content was estimated by the Folin-Ciocalteu method [23]. One $\mathrm{ml}$ of algal suspension was centrifuged at $10000 \mathrm{rpm}$ for $5 \mathrm{~min}$. The pellet was extracted with $1 \mathrm{ml}$ of absolute methanol. 0.5 $\mathrm{ml}$ of the extract was added to test tubes containing $0.5 \mathrm{ml}$ of FolinCiocalteau's phenol reagent and vortexed for $3 \mathrm{~min}$. A $0.5 \mathrm{ml}$ aliquot of $10 \% \mathrm{Na}_{2} \mathrm{CO}_{3}$ solution was then added into the mixture and left in the dark for $1.5 \mathrm{~h}$. Absorbance was then measured at $750 \mathrm{~nm}$. The results were expressed as Gallic acid equivalent (GAE)/g dry weight of microalgae, and calculated as mean value $\pm \mathrm{SD}$.

\section{Data analysis}

Data was evaluated by one-way ANOVA analysis using SPSS software. All significant levels were set at $\mathrm{p}<0.05$.

\section{Results and discussion}

\section{Growth analysis}

The growth of Dunaliella strains before and after high light stress regimens are shown in Figure 1. Growth varied depending on different $D$. salina strains. Of the 3 strains investigated, $D$. salina CCAP produced higher cell numbers than the other strains tested. In general, the cell number of all strains still increased after being subjected to high light stress regimens until day 14 and then decreased rapidly. The cell density of Dunaliella strains under all-time stress regimen of 800 $\mu \mathrm{mol}$.photons $/ \mathrm{m}^{2} / \mathrm{s}$ decreased faster than other regimens except for $D$. bardawil. Statistical analysis for results obtained after stress revealed that there was significant difference in cell density of Dunaliella strains between different regimens. These results indicate that the sensitivity to light intensity under stress regimens is one of attributes involved in the induction of carotenoids.

\section{Carotenoid accumulation}

Under stress conditions D. salina strains had higher total carotenoid induction than those under control conditions (Figure 2). Generally, the strains under all-time stress regimen of $800 \mu \mathrm{mol}$.photons $/ \mathrm{m}^{2} / \mathrm{s} \mathrm{had}$ the highest total carotene based on per $\mathrm{ml}$, per cell and per chlorophyll. However, D. bardawil under the stress regimen involving a cycle of three-days at $800 \mu \mathrm{mol}$.photons $/ \mathrm{m}^{2} / \mathrm{s}$ and one day at $50 \mu$ mol.photons/ $\mathrm{m}^{2} / \mathrm{s}$ revealed better carotene induction per cell than under the all-time stress regimen of $800 \mu \mathrm{mol}$.photons $/ \mathrm{m}^{2} / \mathrm{s}$. The amount of carotene in D. salina CCAP was higher than other strains tested.

\section{Antioxidant capacity}

Regarding antioxidant capacity (per milliliter and per chlorophyll), D. salina CCAP strains under the all-time stress regimen of $800 \mu \mathrm{mol}$. photons $/ \mathrm{m}^{2} / \mathrm{s}$ had the highest amount, and highest total antioxidant capacity. In contrast, $D$. bardawil provided the largest antioxidant capacity per cell. Compared to the total carotene reported, the antioxidant capacity was strongly correlated with the amount of carotene present.

\section{Total phenolic content}

D. salina CCAP showed the highest total phenolic content

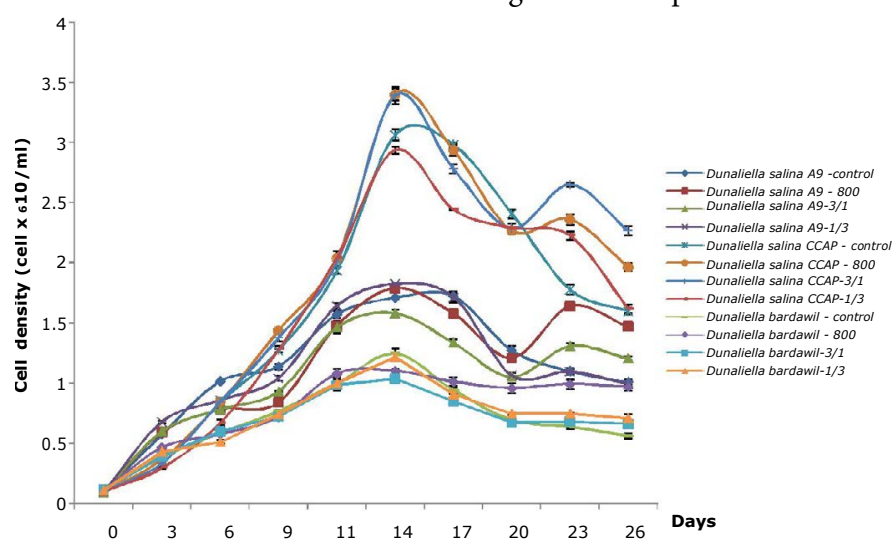

Figure 1. Growth of three Dunaliella salina strains based on cell count (Control: D. salina strains cultured under light intensity of $50 \mu \mathrm{mol}$. photons $/ \mathrm{m}^{2} / \mathrm{s} ; 800$ : D. salina strains stressed under high light intensity of $800 \mu$ mol.photons $/ \mathrm{m}^{2} / \mathrm{s}$ all the time; 3/1: D. salina strains stressed under a cycle of three-day at $800 \mu \mathrm{mol}$.photons $/ \mathrm{m}^{2} / \mathrm{s}$ and one day at 50 $\mu \mathrm{mol}$.photons $/ \mathrm{m}^{2} / \mathrm{s} ; 1 / 3$ : D. salina strains stressed under a cycle of one day at $800 \mu \mathrm{mol}$. photons $/ \mathrm{m}^{2} / \mathrm{s}$ and three-day at $50 \mu \mathrm{mol}$.photons $/ \mathrm{m}^{2} / \mathrm{s}$ ). 




Dunaliella salina A9-control - Dunaliella salina $A 9-800$
- Dunaliella salina $A 9-3 / 1$ - Dunaliella salina $A 9-1 / 3$ - Dunaliella salina CCAP - contro Dunaliella salina CCAP - 800 - Dunanaliellila salina CCAP-31/3 - Dunaliella bardawil - control - Dunaliella bardawil - 800 -Dunaliella bardawi-3/1
-Dunaliella bardawil-1/3

Before stress (Day 11)

Harvest (Day 26)



Before stress (Day 11)

Harvest (Day 26)

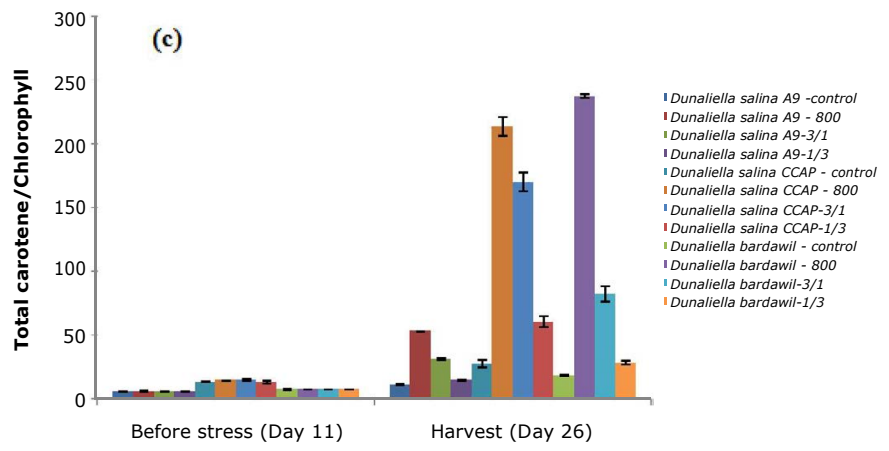

Figure 2. Total carotene of three D.salina strains per milliliter (a), per cell (b), and per chlorophyll (c) (Control: D. salina strains cultured under light intensity of $50 \mu \mathrm{mol}$.photons/ $\mathrm{m}^{2} / \mathrm{s} ; 800$ : D. salina strains stressed under high light intensity of $800 \mu \mathrm{mol}$.photons $/ \mathrm{m}^{2} / \mathrm{s}$ all the time; 3/1: D. salina strains stressed under a cycle of three-day at $800 \mu \mathrm{mol} . \mathrm{photons} / \mathrm{m}^{2} / \mathrm{s}$ and one day at $50 \mu \mathrm{mol}$. photons $/ \mathrm{m}^{2} / \mathrm{s} ; 1 / 3$ : D. salina strains stressed under a cycle of one day at $800 \mu$ mol.photons $/ \mathrm{m}^{2} / \mathrm{s}$ and three-day at $50 \mu \mathrm{mol}$.photons $/ \mathrm{m}^{2} / \mathrm{s}$ ).

compared to other strains tested, especially under the all-time stress regimen of $800 \mu \mathrm{mol}$.photons $/ \mathrm{m}^{2} / \mathrm{s}$ (Figure 4). However, D. bardawil had the largest total phenolic per cell because of their larger cell size. Therefore, total phenolic content appeared to be related to the antioxidant capacity.

\section{Conclusion}

D. salina strains accumulated the highest total carotenoids under the all-time stress at $800 \mu \mathrm{mol}$.photons $/ \mathrm{m}^{2} / \mathrm{s}$ treatment. Moreover, this indicates a strong relationship between the total carotene, total phenolic content and antioxidant capacity. D. salina CCAP provided the largest concentration of carotene, antioxidant capacity and total phenolic content. In contrast, $D$. salina $A 9$ provided the lowest amount in all respects compared to D. salina CCAP and D. bardawil.
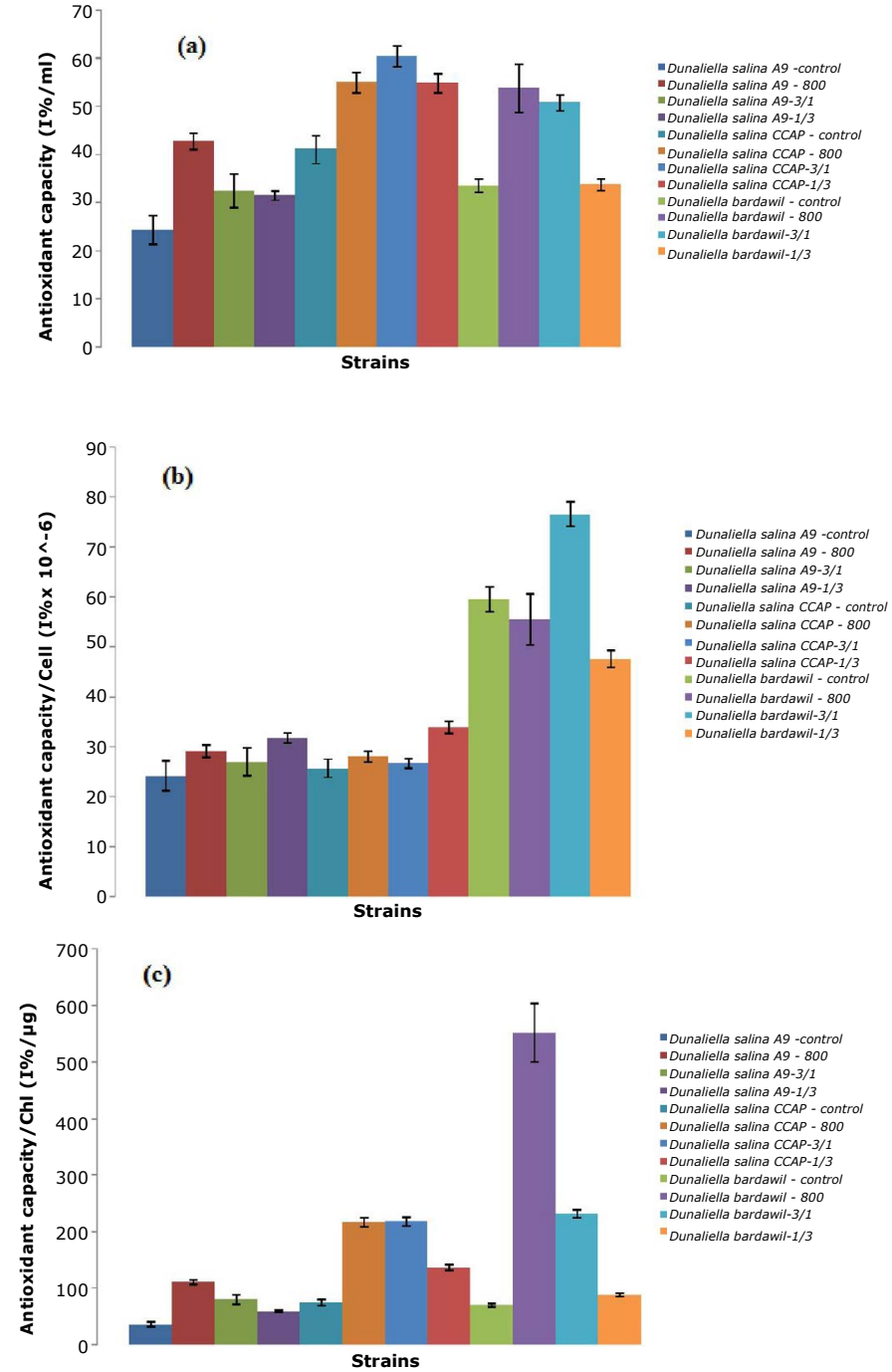

Figure 3. Total antioxidant of three D.salina strains per $\mathrm{ml}$ (a), per cell (b), and per chlorophyll (c) (Control: D. salina strains cultured under light intensity of $50 \mu$ mol.photons/ $\mathrm{m}^{2} / \mathrm{s} ; 800$ : D. salina strains stressed under high light intensity of $800 \mu \mathrm{mol}$.photons $/ \mathrm{m}^{2} / \mathrm{s}$ all the time; 3/1: D. salina strains stressed under a cycle of three-day at $800 \mu \mathrm{mol}$.photons $/ \mathrm{m}^{2} / \mathrm{s}$ and one day at $50 \mu \mathrm{mol}$.photons $/ \mathrm{m}^{2} / \mathrm{s} ; 1 / 3$ : D. salina strains stressed under a cycle of one day at $800 \mu \mathrm{mol}$.photons $/ \mathrm{m}^{2} / \mathrm{s}$ and three-day at $50 \mu \mathrm{mol}$.photons $/ \mathrm{m}^{2} / \mathrm{s}$ ).

This unique property of $D$. salina to accumulate large amount of carotenoids when grown under unfavorable conditions can be exploited for industrial applications. More importantly, new discoveries in regards to the health benefits effects of $\beta$-carotene, such as its anticarcinogenic properties will undoubtedly promote demand of this natural compound. An increase demand will consequently promote further commercial development including novel biotechnological purposes, opening thereby completely new scientific areas in Dunaliella technology. However, in order to have a competitive edge in the marketplace, other forward looking approaches furthering the development of Dunaliella will have to be put forward.

\section{References}

1. Massjuk NP (1972) On phylogeny and taxonomy of the genus DunaliellaTeod.Ukr Bot. Zh. 29: 744-750.

2. Pick U (1998) Dunaliella-A model extremophilic alga. Israel Journal of Plant Sciences 46: 131-139. 

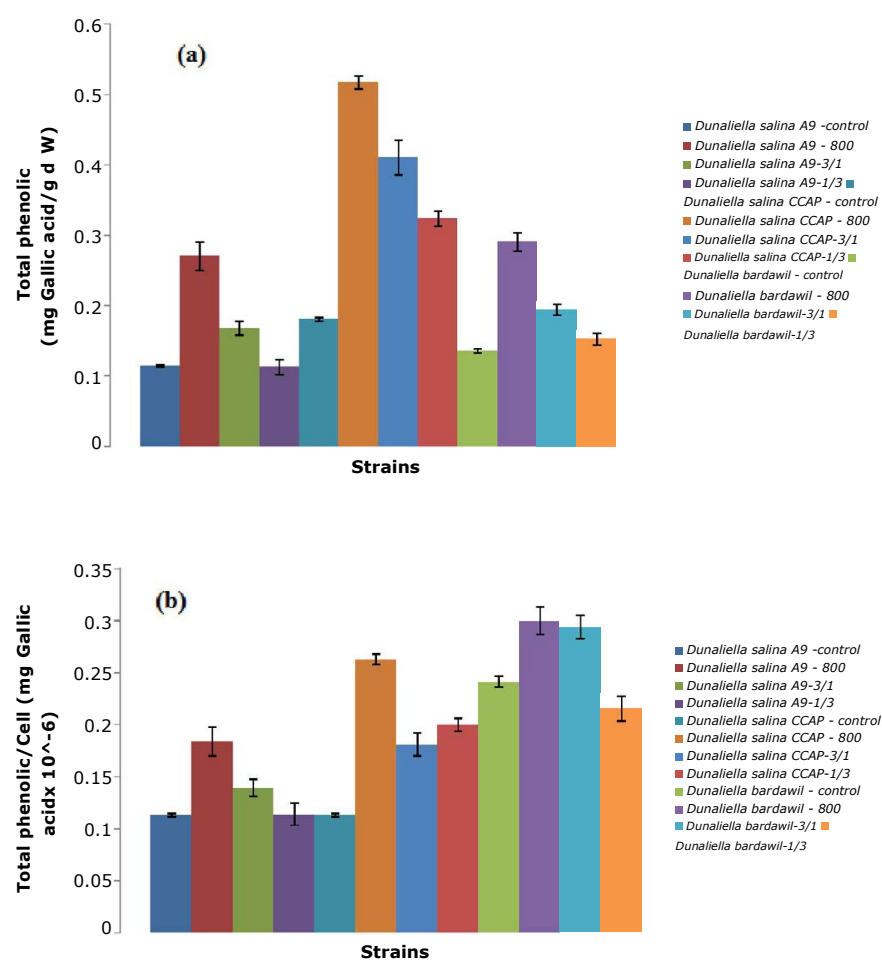

- Dunaliella salina $A 9$-control
Dunaliella salina $A 9-800$ - Dunaliella salina A9-3/1 Dunaliella salina A9-1/3 - Dunaliella salina CCAP - contro - Dunaliella salina CCAP-3/1 - Dunaliella salina CCAP-1/3 Dunaliella bardawil - control -Dunaliella bardawil-3/1 1 Dunaliella bardawil-1/3

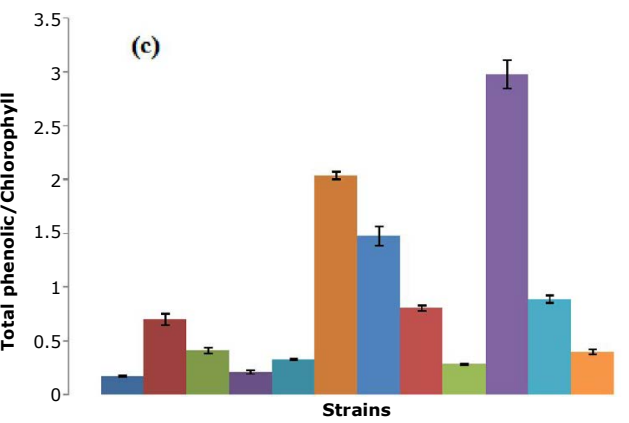

- Dunaliella salina $A 9$-control
- Dunaliella salina $A 9-800$ Dunaliella salina $A 9-800$
DDunaliella salina $A 9-3 / 1$ - Dunaliella salina $A 9-1 / 3$ IDunaliella salina CCAP - control

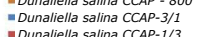
Dunaliella bardawil - control - Dunaliella bardawil -800
"Dunaliella bardawil-3/1 "Dunaliella bardawil-1/3

Figure 4. Total phenolic of three D. salina strains per $\mathrm{ml}$ (a), per cell (b),and per chlorophyl (c) (Control: D. salina strains cultured under light intensity of $50 \mu \mathrm{mol}$.photons $/ \mathrm{m}^{2} / \mathrm{s} ; 800$ D. salina strains stressed under high light intensity of $800 \mu$ mol.photons $/ \mathrm{m}^{2} / \mathrm{s}$ all the time; 3/1: D. salina strains stressed under a cycle of three-day at $800 \mu \mathrm{mol} . \mathrm{photons} / \mathrm{m}^{2} / \mathrm{s}$ and one day at $50 \mu \mathrm{mol}$.photons $/ \mathrm{m}^{2} / \mathrm{s} ; 1 / 3$ : D. salina strains stressed under a cycle of one day at 800 $\mu$ mol.photons $/ \mathrm{m}^{2} / \mathrm{s}$ and three-day at $50 \mu$ mol.photons $/ \mathrm{m}^{2} / \mathrm{s}$ ).

3. Oren A (2005) A hundred years of Dunaliella research: 1905-2005. Saline Systems 1: 2. [Crossref]

4. Borowitzka MA, Siva CJ (2007) The taxonomy of the genus Dunaliella (Chlorophyta, Dunaliellales) with emphasis on the marine and halophilic species. Journal of Applied Phycology 19: 567-590.

5. Polle JEW, Tran D, Ben-Amotz A (2009) Chapter 1: History, Distribution, and Habitats of Algae of the Genus Dunaliella TEODORESCO (Chlorophyceae). Book in press: The Alga Dunaliella: Biodiversity, Physiology, Genomics \& Biotechnology.

6. Ben-Amotz A, Shaish A (1992) B-Carotene bio-synthesis. In: Avron, M., Ben-Amotz, A. (Eds.), Dunaliella: Physiology, Biochemistry and Biotechnology. CRC Press, Boca Raton, FL: 206-216.

7. Denery JR, Dragull K, Tang CS, Li QX (2004) Pressurized fluid extraction of carotenoids from Haeatococcuspluvialis and Dunaliellasalina and kavalactones from Piper methysticum. Analytica Chimica Acta 501: 175-181.

8. Garci 'a-Gonza 'lez M, Moreno J, Manzano JC, Florencio FJ, Guerrero MG (2005) Production of Dunaliellasalina biomass rich in 9-cis-b-carotene and lutein in a closed tubular photobioreactor. Journal of Biochemistry 115: 81-90.

9. Raja R, Hemaiswarya S, Balasubramanyam D, Rengasamy R (2007) Protective

effect of Dunaliellasalina (Volvocales, Chlorohhyta) against experimentally induced fibrosarcoma on wistar rat. Microbiological Research 162: 177-184.

10. Boussiba S, Vonshank A (1991) Enhancement and Determination of astaxanthin accumulation in the green alga Haematococcuspluvialis. Methods in Enzymology 213: 386-391.

11. Ausich RL (1997) Commercial opportunities for carotenoid production by biotechnology. Pure Appl. Chem. 69: 2169-2173.

12. Sandmann G (2001) Genetic manipulation of carotenoid biosynthesis: strategies, problems and achievements. Trends Plant Sci 6: 14-17. [Crossref]

13. Rock CL (2002) Carotenoids and cervical, breast, ovarian, and colorectal cancer: Epidemiology and clinical trials. Pure Appl Chem 74: 1451-1459.

14. Russell RM (2002) B-carotene and lung cancer. Pure Appl Chem 74: 1461-1467.

15. Borowitzka LJ, Borowitzka MA (1990) Comercial prodution of $\beta$ - carotene by Dunaliella salina in open ponds. Bull Mar Sci 47: 244-252.

16. Cifuentes AS, Gonzalez MA, Parra OO (1996) The effect of salinity on the growth and carotenogenesis in two Chilean strains of Dunaliella salina Teodoresco. Biol Res 29: 227-236. [Crossref]

17. Ben-Amotz A, Lers A, Avron M (1988) Stereoisomers of beta-Carotene and Phytoene in the Alga Dunaliella bardawil. Plant Physiol 86: 1286-1291. [Crossref]

18. Araneda P, Jiménez C, Gómez-Silva B (1992) Growth and beta-carotene content of three isolates of Dunaliellasalina from the Atacame Desert. Revista de Biología Marina de Valparaíso (Chile) 27: 157-162.

19. Tran D, Doan N, Louime C, Giordano M, Portilla S (2014) Growth, antioxidan capacity and total carotene of Dunaliella salina DCCBC15 in a low cost enriched natural seawater medium. World J Microbiol Biotechnol 30: 317-322. [Crossref]

20. Shaish AA, Ben-Amotz, M Avron (1992) Biosynthesis of B- carotein in Dunaliella. Methods Enzymol. 213: 439-444.

21. Romeilad RM, Fayed SA, Mahmoud GI (2010) Chemical compositions, Antiviral and Antioxidant activities of seven essential oils. Journal of Applied Sciences Research 6 : $50-62$.

22. Das KB, Das B, Arpita FK, Morshed MA, Uddin A (2011) Photochemical screening and antioxidant activity of Leucasaspera. IJPSR 2: 1746-1752.

23. Singleton VL, Rossi JA (1965) Colorimetry of total phenolics with phosphomolybdicphosphotungstic acid reagents. American Journal of Enology and Viticulture 16: 144-153.

Copyright: (C2016 Nguyen A. This is an open-access article distributed under the terms of the Creative Commons Attribution License, which permits unrestricted use, distribution, and reproduction in any medium, provided the original author and source are credited. 